\title{
Pedagogical Tools for Teaching Exploration
}

\author{
Terence Reilly \\ Babson College
}

\begin{abstract}
A common problem faced in post-secondary education is how do we move our students past being satisfied with the first answer they find and to a more thoughtful, more complete, and more nuanced solution? Once our students have 'solved' a case problem, they believe there is nothing more to do. Students, especially freshmen and sophomores, are not accustomed to exploring the case situation for additional insights beyond the first solution. This paper presents two pedagogical tools that have dramatically improved my students' performance in using the methods presented in the classroom. These tools have helped my students understand how to go beyond the first solution and explore the situation from more than their own perspective and thereby gain valuable insights into the situation. The first tool is a two-step grading procedure, in which I grade both a rough draft and a final draft. Instead of the grading being a punitive exercise, it has become a way to guide and further educate my students. The second tool is specifically designed inclass demonstrations that highlight the improvements that result when exploring beyond the first solution.
\end{abstract}

Keywords: Cooperative Learning; Grading Case Reports; Mathematical Models

\section{Introduction}

One of the main differences between secondary and post-secondary education is that college and graduate students are expected to go beyond simply applying the concept to becoming proficient with them. In my mathematical modelling classes, I expect my students to not be satisfied with their first model and solution; rather, I want them to treat it as a first approximation that can be improved. I spent many frustrating years pushing and prodding my students, especially freshman and sophomores, to dig deeper into the analysis, to explore the situation from more than their own perspective, and to use the model to explore for improved solutions. I present here two pedagogical tools that have (based on anecdotal evidence) dramatically improved my students' performance. These tools have helped the students understand that by exploring, they can find more nuanced solutions and gain valuable insights into the situation.

\section{Pedagogical Tools}

These tools came about after I took some responsibility for the students' failures and assessed why it was they were satisfied with their first solution. Finding the answer, then moving on to the next problem was certainly learned behaviour on their part, which I tried (unsuccessively) to counter. I started using the case teaching methodology (Christensen, 1981) and replaced my exams with case reports (Dehler, 1996; Emig, 1977). Although the case reports were helpful, students were still struggling with how to explore the situation for additional insights.

I provided extensive feedback on their case reports, that is, their deliverables. I was spending from 30 - 40 minutes grading each student's deliverable carefully pointing out various ways they could have improved their model and solution. All this time and effort spent pointing out their mistakes only made them feel they had no mastery of the subject and frustrated me as they would make the same type of mistakes on the next deliverable. True, by the end of the semester, they were performing better, but it was a frustrating path for both parties. 
Using Value-Focused Thinking (Keeney, 1992), I asked what was it I wanted to obtain and what were my means? This lead me to the realization that, in a perfect world, I wanted to be pre-emptive and advise students on ways to improve their model before they handed it in for grading. Somehow, I wanted to help, but without doing their work for them. I wanted a way to advise them on improvements, on ways they could further explore case, but only after they put a substantial amount of work into the deliverable. I discovered two ways to be preemptive: in-class demonstrations focused on exploration and a two-step grading procedure. First, I discuss the two-step grading procedure and then provide two examples of actual in-class demonstrations.

\section{Two-Step Grading Procedure}

Students often only do the minimum analysis in their deliverable and do not explore the data or model for additional insights. Students will often ask: "Do we need to report on the sensitivity analysis?" "How many hypotheses tests do we need to do?" or "Which regression is the right one?" These questions are as frustrating as the proverbial "Will this be on the test?” One solution is to use a two-step grading procedure, where I grade both a rough draft and a final paper. This allows me to provide feedback via the rough draft directing the students toward further explorations of the material.

I use cooperative-learning techniques by assigning each member of a four-person group a specific role. For each case report, I assign two roles and have two deliverables. After the group, as a whole, builds the model and does the analysis for a specific case, I assign, a subgroup of two to write a rough draft of the paper and the other two members are responsible for the final draft.

Key to the procedure is that I grade the rough draft. Knowing that it will be graded, the students work surprisingly hard on their rough draft. I typically, assign a weight of $50 \%$ of the deliverable's weight to the rough draft. This high weight has led to rough drafts comparable to the final drafts of students in a typical course. The two students responsible for writing the rough draft have peer pressure to do well and, as these papers are between 20 and 35 pages in length, a rough draft is a substantial amount of work. As the group of four receive only one score, there is often editing and collaboration from the other two members.

Another advantage of grading the rough draft is that it allows me to furnish copious comments on improvements to both the writing and the mathematical analysis. Whereas before I was never sure my comments were being read, the comments in the rough draft are not only being read, but also acted on. I now feel that the 20 minutes required to grade each rough draft is time well spent. Instead of these comments being taken as punitive by the students, the students actually see additional ways to explore the situation. For those students who missed the point of the case, I can nudge them back to the correct analysis. For all the students, I suggest possibilities and scenarios they can investigate. With these improvements in hand, the whole group meets a second time to carry out the suggested analysis (and hopefully go beyond). Then, the two remaining group members are assigned to write the final draft. I typically have three to four deliverables per semester and rotate the group roles for each one.

Instead of following a one-step grading procedure (grade deliverable, providing feedback and hoping the next one will be better), I use a two-step procedure (grade rough draft, grade final draft). Students work hard on the analysis and the paper knowing that it will be graded. Being able to provide suggestions, hints, comments, etc. on the rough draft is an excellent way for students to learn how to master a subject. 
They see what they did, what could be done, and they have the opportunity to carry out the additional modeling and analysis. Instead of being penalized, they can proudly show they do understand the material and enjoy the class more.

Grading each paper twice certainly increases my workload, but not by $200 \%$. I read the rough drafts closely and spend most of my grading time on them as I know they will be scrutinized and acted on. The final draft is read and graded relatively quickly. I make only minimal comments on the final draft, greatly speeding up the process. Thus, for me, the two-step procedure takes about $25 \%$ longer than the traditional method.

I conclude by noting that when the whole group gets together to build and analyse the model, I assign cooperative learning roles (Barkley, Cross, \& Major, 2005) to each group member. Typically, I assign one student to be the Reporter, who writes down all the questions, all the insights, and anything else the group wants recorded. I assign one student to be the Questioner, who asks questions about the model, the analysis, the interpretations of the results, and ways to improve the analysis. Finally, the other two group members are Analysts and carry out the model building and analysis with input and suggestions from all group members.

Over the years, the feedback from these projects has been phenomenal and many students have discussed these papers in their job interviews. The students are proud of their work, and recruiters have been impressed with our student's ability to communicate to a lay audience.

\section{In-Class Demonstrations}

In addition to a two-step grading procedure, I use in-class demonstrations and breakout sessions focused on showing students how to go beyond the first solution and find improved and more nuanced solutions. I now present two of these demonstrations, one in optimization and one in simulation. With the optimization example, I discuss exactly how to go beyond the first answer and with the simulation example, I only point out model extensions that are possible and straightforward.

\section{Optimization Demonstration}

Len owns Back Bay Sports, a sports store that stocks 3 types of bicycles - road racing, touring bikes, and mountain bikes. The cost per bike, the sales price, and the time it takes to assemble and sell a bike are given in Table 1 broken down by type. Len has space for 35 bikes in his store and has allocated a budget of $\$ 72,000 /$ month for purchasing bikes. He has staff that assembles and sells the bikes and has allocated 200 hours/month for assembly and sales. Len also sells at least twice as many mountain bikes as the other two combined. Assuming Len sells every bike he orders, how many bikes by type should he order each month?

Table 1. Break down of costs, revenue, and staff hours for Back Bay Sports

$\begin{array}{lcll} & \text { Road Racing } & \text { Touring Bikes } & \text { Mountain Bikes } \\ \text { Cost/bike } & \$ 3,200 & \$ 2,100 & \$ 2,800 \\ \text { Sales Price } & \$ 4,500 & \$ 3,000 & \$ 4,000 \\ \text { Assembly \& Sales } & 8 \mathrm{hrs} / \mathrm{bike} & 6 \mathrm{hrs} / \mathrm{bike} & 10 \mathrm{hrs} / \mathrm{bike}\end{array}$


The above problem (modified from Taylor, 2013) is one of the first models students work on when we are building optimization models. The students and I build it together, me at the podium and them following on their laptops. After a discussion on Len's objectives, deciding to maximizing profit, we derive the mathematical equations describing the model, then insert these into Excel. The first solution shows that Len maximizes his marginal profit by ordering 7.14 road bikes, 0 touring bikes, and 14.28 mountain bikes resulting in a marginal profit of \$26,429/month.

The first discussion point of the results is the non-integer solution values; how can Len order 7.14 bikes? I mention that next week we cover an advanced solution method, called integer programming that is designed to only give integer solutions. As we have yet to learn this, we must work with this solution. As a class, we decide if we should round up our solution or truncate the order quantities to integers. One of the hardest lessons for students to learn in mathematical modelling classes is that their model is only an approximation. Students want to incorporate each and every aspect of the problem or situation into the model. Thus, I point out that this is a situation in which we forego one aspect of the problem (integer solutions) so that we can build and solve the model.

The next set of discussion points focuses on Excel's Answer Report, which shows that the budget of \$72,000 and the space to hold 35 bikes are non-binding constraints while the mountain bike ratio and staff hours are binding. Here the students learn that the only way to increase Len's monthly profit is to relax a binding constraint. For example, Len is only using $\$ 62,857$ of the allotted $\$ 72,000$. Thus, relaxing this constraint does not help Len at all. However, what happens if we relax either the mountain bike ratio or the staff hours? By exploring this idea, we can (perhaps) find a better solution for Len.

To explore relaxing these constraints, we turn to Excel's Sensitivity Analysis Report, particularly, the shadow price for staff hours. The shadow price is $\$ 132$, meaning that each additional staff hour increases Len's profit by $\$ 132$. As Len is not paying his staff $\$ 132 / \mathrm{hr}$, it is cost effective for Len to increase staff hours. How many additional hours should Len add? Again, the Sensitivity Analysis report tells us: add at least 29.09 hours. Note that the students are learning how to interpret the model's reports not in the abstract, but towards a specific goal, viz., increasing maximum profit.

As a class, we add 30 hours to the monthly staff hours, upping the bound from 200 to 230 hours, and rerun the optimization model. We are now on our second solution, which reports that Len maximizes profit by ordering 7.7 road bikes, 0.60 touring bikes, and 16.5 mountain bikes resulting in a marginal profit of $\$ 30,311 /$ month. Therefore, we increased monthly profit by $\$ 3,882$ by adding 30 staff hours. I make sure to point out that we have increased Len's marginal profit by more than $\$ 45,000$ annually simply by exploring the model and solution for improvements.

We see Len now needs all $\$ 72,000$ of his budget and he has three binding constraints: the budget, the mountain bike ratio, and assembly \& sales hours. I tell the class that we ignore the MTB Ratio constraint until next class and, turning to the new Sensitivity Analysis report, the shadow price for the budget constraint is $\$ 0.29$ and is $\$ 41.67$ for the assembly \& sales constraint. Again, focusing on assembly \& sales, we can add up to 13.1 hours and the marginal profit will increase by $\$ 41.67$ per added hour. Adding 14 hours to the monthly staff hours for a new upper bound of 244 hours, we have our third solution, which reports that Len maximizes profit by ordering 0 road bikes, 9.4 touring bikes, and 18.7 mountain bikes resulting in a marginal profit of $\$ 30,857 /$ month. This is a \$547 increase from solution two and a \$4429 increase over the first solution. 
At this point, the students break into groups to explore relaxing the budget constraint as an in-class exercise. After successive explorations, the budget should be raised to $\$ 76,686$ with a monthly profit of $\$ 32,243$-an increase of $\$ 1,386$.

Not only has exploring the situation improved Len's profitability, but we have also discovered a number of insights into the optimal bike order. We found that restricted staff hours was not saving Len money, but costing him $\$ 132 / \mathrm{hr}$. We also see that optimal order quantity for the bikes is quite sensitive to the bounds. For example, when staff hours had a 200 hour bound, then Len should order 7 road racing bikes, but when the bound is 244 hours, then he should order 0 road bikes. Moreover, when the budget bound increases to $\$ 76,686$ and the staff bound stays at 244 hours, then he should order 8 or 9 road bikes. All these insights help Len make his order decision and came about from exploring the model and solution.

From, this point, there are many different directions this problem can be taken. For example, we could add hourly rate for staff, such as \$25/hour. This will allow us to subtract the staff costs from the marginal profit thereby improving the model. We could also explore adding integer constraints, so that there are no factional bicycles being bought and sold.

\section{Simulation Demonstration}

As the manager of a local college bookstore, every September, we must decide how many calendars to order. The calendars arrive October 1st and are displayed until January 31st, after which all unsold calendars are returned to the publisher for a small refund. Specifically, each calendar costs $\$ 4.25$, which we retail for $\$ 11.95$, and unsold calendars are refunded at $\$ 1.45$ each. Using past sales data combined with current estimates of market conditions, our best guess of the distribution of the number of calendars demanded is given in Table 2.

How many calendars should we order? What are the associated risks?

Table 2. Distribution of Demand

\begin{tabular}{|c|c|}
\hline Demand & Probability \\
\hline 500 & .10 \\
\hline 550 & .25 \\
\hline 600 & .35 \\
\hline 650 & .20 \\
\hline 700 & .10 \\
\hline
\end{tabular}

The above problem is adapted from Winston (2004). Instead of walking though the exploration of the solution, I discuss natural ways to extend the base model.

After solving the model together, I ask the students how to extend the model - In what ways can we modify the model to make it better? Students struggle at first, but after some help, they start to offer suggestions. First, we replace the discrete distribution given in Table 2 with a continuous distribution. This allows us to discuss types of distributions, such as normal or triangular. We can model multiple products instead of just selling calendars. We then discuss ways to incorporate the relationship between two products. Are the products substitutes for one another or are the complementary or 
are they not related at all? This allows us to discuss how to use correlations or regression equations to model dependency.

\section{Conclusions}

The results in this paper are all anecdotal, based on my classroom experiences, and I have found these two pedagogical tools to be quite helpful. Students are not accustomed to thinking critically of their solution, but they need this ability (Bobrowski \& Cox, 2003). Case reports are an excellent vehicle as the students must write and think about what the analysis means to them and the decision maker. To further help my students explore the situation, I grade both a rough draft paper and their final. I spend considerable time providing feedback on the rough draft, thereby providing individual guidance to each report. I also use in-class demonstrations coupled with breakout sessions that are focused on methods to explore the situation.

\section{References}

Barkley, E. F, Cross, K. P. \& Major, C. H. (2005). Collaborative Learning Techniques: A Handbook for College Faculty. San-Francisco: Jossey-Bass.

Bobrowski, P. E. and Cox, P. L. (2003). Critical Thinking Exercise: Causes of Premature Death in America. Decision Sciences Journal of Innovative Education, 1: 145-149.

Christensen, C. R. (1981). Teaching By the Case Method. Boston: Harvard Business School.

Dehler, G. E. (1996). Management education as intentional learning: A knowledgetransforming approach to written composition. Journal of Management Education, 20(2), 221-235.

Emig, J. (1977). Writing as a model of learning. College Composition and Communication, 28, 122-128.

Keeney, R. (1992). Value-focused thinking: A path to creative decisionmaking. Cambridge, Mass.: Harvard University Press.

Taylor, B.W. (2013). Introduction to Management Science, Eleventh Edition. Custom Edition for Babson College, Boston: Pearson Custom Publishing.

Winston, W. (2004). Financial models using simulation and optimization (3rd ed.). Newfield, NY: Palisade. 